\title{
School enrollment in the Democratic Republic of the Congo: family economic well-being, gender, and place of residence ${ }^{l}$
}

\author{
Crispin Mabika Mabika \\ University of Kinshasa, Department of Population Sciences and \\ Development, B.P. 176, Kinshasa XI \\ Democratic Republic of the Congo \\ crispin.mabika@unikin.ac.cd; mabika_cris@yahoo.fr \\ David Shapiro ${ }^{2}$ \\ Pennsylvania State University, Department of Economics \\ 416 Kern Graduate Building, University Park, PA 16802 \\ United States of America \\ 1-814-863-1533 (phone), 1-814-863-4775 (fax) \\ dshapiro@psu.edu
}

August 2012

\begin{abstract}
This paper examines school enrollment of youth in the Democratic Republic of the Congo (DRC), to identify the roles of family economic well-being, gender, and place of residence in the school enrollment of children. The DRC experienced extremely adverse economic and political conditions during the 1990s. We use data from a 1999 survey that covered four provinces in the western portion of the country. Following an overview of the country's economic situation, the paper examines descriptive data on school enrollments of more than 9,000 youth aged 6-24. We then report results of multivariate analyses of school enrollment of more than 6,000 youth aged 6-14, controlling for family economic well-being, gender, and place of residence as well as a number of other factors. All three of the key variables are relevant to being in school, but in each case the impacts are dependent on the other two variables.
\end{abstract}

\section{Résumé}

Cet article examine l'inscription scolaire des jeunes en République démocratique du Congo (RDC), afin d'identifier l'importance de l'influence du bien-être économique de la famille, du genre, et du lieu de résidence sur la scolarisation des

I. Revised version of a paper presented at the Union for African Population Studies Sixth African Population Conference, Ouagadougou, Burkina Faso, 5-9 December 20II. We thank Guanhao Feng, Alex Cadmus, and Nathan Bartell for excellent research assistance, and acknowledge helpful reviewer comments. Financial support from Bates White, LLC, through the Research Experiences for Undergraduates Program in the Penn State Economics Department, is gratefully acknowledged. Responsibility for the contents of the paper rests with the authors.

2. Corresponding author. 
jeunes. La RDC a subi des conditions économiques et politiques extrêmement sévères pendant les années 1990. Les données proviennent d'une enquête qui a eu lieu en 1999, et qui a couvert quatre provinces dans la partie occidentale du pays. Nous commençons avec un aperçu de la situation économique du pays, suivi par un examen des données descriptives concernant les inscriptions scolaires de plus de 9.000 jeunes âgées de 6 à 24 ans. Ensuite nous abordons les résultats des analyses multivariées de l'inscription scolaire de plus de 6.000 jeunes âgés de 6 à 14 ans, en tenant compte du bien-être économique de la famille, du genre, et du lieu de résidence ainsi que quelques autres facteurs associés. Toutes les trois variables clés sont pertinentes à la scolarisation, mais dans chaque cas l'impact dépend du contrôle des deux autres variables.

Keywords: School enrollment, Democratic Republic of the Congo, economic well-being, gender, place of residence

\section{Introduction}

The Millennium Development Goals include the goal of achieving universal primary education. While there has been progress made toward this goal, it is still the case that in sub-Saharan Africa, much remains to be done to increase the percentage of youth who are enrolled in school (Lloyd and Hewett, 2003; Pilon and Wayack, 2003; Moguéorou, 20II), and a number of scholars have argued that the Millennium Development Goals will likely not be attained for quite some time for a number of countries in the region (eg. Hugon, 2007; Lange, 2007).

Low incomes at the microeconomic level and poor economic performance at the macroeconomic level are among the factors that constrain children's participation in school (Rebouha and Pochet, 20II). There is considerable evidence that in developing countries, family economic well-being is a key determinant of children's access to and progress in school (eg. Schultz, 1993; Knodel and Jones, 1996; Lloyd and Blanc, 1996; Kaboré and Pilon, 2003; Lloyd and Hewett, 2003; Huisman and Smits, 2009; Kazeem et al., 2010).
In addition, in many developing country settings there are distinct gender differences in favor of boys in the school enrollment of youth (see Proteau, 1998; Glick and Sahn, 2000; Huisman and Smits, 2009; Kazeem et al., 2010). It is worth noting, however, that Lloyd and Hewett (2003) present evidence suggesting that the gender gap in primary education in sub-Saharan Africa has diminished considerably over time, reflecting growth in school enrollment rates of girls in conjunction with stagnation of enrollment rates of boys. Lloyd and Hewett echo an argument made earlier by Knodel and Jones (1996), suggesting that differences by economic well-being in access to and participation in schooling have become more important than differences by gender.

Further, enrollment differences by place of residence are often evident in developing countries, with urban youth typically having greater access to school and higher school enrollment rates than their rural counterparts (Ersado, 2005). Taken together, then, these considerations would seem to suggest that the most difficult group to attain in efforts to achieve universal primary education 
would be rural females from poor families.

At the same time, however, as Kazeem et al. (20l0) and others emphasize, there are interactions among these three factors - economic well-being, gender, and place of residence - so differences in one of these key variables may vary depending on the status of the other two variables. For example, gender differences may vary by place of residence, and given place of residence, they may also vary by economic well-being. Huisman and Smits (2009) explore interaction effects in their study, and find, for example, a disadvantage for rural girls compared to urban girls, other things being equal, that is not present for boys. Glick and Sahn (2000), in their examination of investments in schooling in Conakry, Guinea, find that higher family economic well-being was associated with greater investment in the schooling of girls, but not of boys. Lloyd and Hewett (2003) provide evidence that there are greater gender inequalities among the poor. Ersado (2005) argues that poverty drives schooling decisions in rural areas but not in urban places, and Kazeem et al. (2010), in their study of Nigeria, conclude that the rural disadvantage is almost entirely accounted for by differences in household wealth.

Consequently, it is useful to examine different case studies, so as to compare and contrast differences by economic well-being, gender, and place of residence that exist in different settings. This paper examines school enrollment in the Democratic Republic of the Congo (DRC), with a view to identifying the roles of family economic well-being, gender, and place of resi- dence as influences on the school enrollment of children. In our multivariate analyses we also control for other social and demographic factors, including child fostering, household size and composition, and parental educational attainment, among others, that come into play as factors influencing school enrollment.

The DRC constitutes a case study of particular interest because of the extremely adverse economic conditions experienced during the 1990s. Examination of data from the Penn World Table (Heston et al., 20I I) for close to three dozen countries in sub-Saharan Africa shows that the DRC had by far the worst overall economic performance since 1990, and as discussed below, the bulk of the adverse economic circumstances were experienced during the 1990s. Hence, while other research has looked at the effects of our key variables on school enrollment, this study will allow us to see if we find similar effects in the presence of extremely adverse economic circumstances.

Results reported below are drawn from the doctoral dissertation of Mabika (2010). We use data from a 1999 survey that covered four provinces in the western portion of the Democratic Republic of the Congo. The survey took place at the end of a disastrous decade for the DRC, during which economic crisis, civil disorder, and then civil war were all prevalent (De Herdt and Marysse, 1997; De Herdt, 2000).

There has been research on factors influencing school enrollment and educational attainment in the DRC, including economic well-being and gender, 
but that research has been focused on the capital, Kinshasa (see Shapiro and Tambashe, 1999, 2001, 2003, and Shapiro, 2010). Further, most of those studies pertained to data collected prior to the severe economic downturn that began in 1990. In addition, Kinshasa is unique within the DRC - it is entirely urban, and its population, relative to the rest of the country, is both economically better off and also better-educated. Kinshasa is one of the four provinces (out of I I nationally) covered in this study's data. The availability of data for three other provinces, largely rural but each with some urban centers, provides a more complete picture of children's access to schooling in the DRC and differences by economic wellbeing, gender, and place of residence manifested during a period of extremely adverse economic circumstances.

To provide some context, the following section of the paper reviews the economic difficulties experienced by the DRC over the past 35 years. In brief, this review makes it clear that a protracted period of poor economic performance from the mid-1970s until 1990 was followed by a decade of an initially more severe and steady economic decline beginning in 1990. Subsequent to the overview of the economic situation, we discuss the likely determinants of school enrollment of youth in the Congo. The paper then examines descriptive data on school enrollments, with a focus on differences by gender, economic well-being, and place of residence. The final substantive section of the paper, after the descriptive analyses, reports and discusses results of multivariate analyses of school enroll- ment. The conclusions will briefly summarize and then discuss the implications of our research findings.

\section{Enduring economic difficulties in the Congo}

Following independence from Belgium in 1960, the Congo experienced five years of political instability, including civil war and ethnic strife. In 1965 General Joseph Désiré Mobutu seized power in a coup d'état, and for the better part of a decade the city and the country experienced a period of political stability and economic growth. The former would continue, more or less, but not the latter. In particular, by the mid-1970s the combined effects of poor economic policies (including expropriation of businesses owned by foreigners and turning those businesses over to unqualified nationals, known then as Zairians) and the sharp decline in world copper prices that took place about that time (copper was by far the major source of export earnings and government revenues) were to precipitate a long, downward slide of the Congolese economy. Exacerbating the situation was the fact that the Mobutu regime was characterized by extremely high levels of corruption at all levels of government - what some political scientists referred to as "kleptocracy." This further contributed to a period of chronic poor economic performance.

Economic growth from year to year was highly variable, and more often negative than positive. Likewise, inflation was persistent, ranging from roughly 25 to over 100 percent per year (Shapiro and Tollens, 1992), and the standard of living of the population (as measured by real GDP per capita) 
declined by more than 35 percent between 197I and 1990 (Heston et al., 20II). This chronic poor economic performance was accompanied by stagnation in the modern sector of the economy and steady growth in the informal sector (Shapiro and Tambashe, 2003).

Beginning in the latter half of 1990 , the chronic poor economic performance became acute. After a number of years of inflation averaging roughly 60 percent per year, very rapid inflation of 2,000-3,000 percent per year quickly emerged, as the country's monetary authorities essentially abandoned any efforts to adhere to a structural adjustment program that had been adopted in the 1980s. The country was already in turmoil politically, with increasing calls for democracy and the ouster of President Mobutu. Following a little more than a year of very rapid inflation, in late September of 199I soldiers, who had seen the real value of their salaries shrink to nearly nothing, initiated rioting, looting and generalized civil disorder, first in Kinshasa and then in urban centers elsewhere in the country. The modern sector of the country's economy, much of it based in Kinshasa, shrank considerably, and foreign donors pulled out of the country. A second round of looting and pillaging, this time only by the military, took place at the end of January in 1993.

A rebellion that began in late 1996 and that was made possible by assistance from neighboring Rwanda resulted in the ouster of President Mobutu in May of 1997, but civil war reemerged in 1998. Rwanda and a number of other African nations were involved in the civil war, which continued officially until
2003 and resulted in substantial loss of life and destruction of infrastructure. The 1990s, then, was a decade of severe downward economic spiral in the DRC and in Kinshasa, along with considerable chaos politically.

Estimated real GDP per capita for the Congo for the period since 1970 (data are from the Penn World Table, Heston et al., 20II) shows that from a peak of just over $\$ 1,120$ in 197I, real GDP per capita fell by almost 80 percent, to only about $\$ 231$ in 2009 . But for the period from 1990-1999, the decline in real GDP per capita was almost 75 percent. That is, if one looks at year-to-year changes, it is apparent that between 1974 and 1990 the economic situation was bad: negative growth was realized during ten of the 16 years. But after 1990 the situation was terrible: during the 1990s, there was negative growth in all but one year.

Given the lengthy period of substantial economic deterioration in the DRC, one would anticipate that school enrollment data from 1999 would reflect that poor economic performance. Before examining the data, we turn to a consideration of likely determinants of school enrollment in the Congo.

\section{Determinants of school enrollment}

Schooling of children constitutes an investment in their human capital, and there are a number of factors that are likely to affect the propensity of parents to send their children to school. As a prelude to discussion of these different factors, it is useful to recall that school is but one of several activities in which young people may engage. In develop- 
ing-country settings such as the Congo, work and leisure are both potential activities for youth. We will not consider leisure here. Work, in turn, may entail work in the labor market or work at home. For the 6-14 age group that will be the focus of our multivariate analyses of school enrollment below, labor market work would consist of work in the informal sector of the economy. Work at home might entail contribution to household agricultural production and/or performing household chores, such as fetching firewood or water or caring for younger siblings.

From this perspective, then, household economic well-being is expected to be an important determinant of the school enrollment of youth, particularly in a low-income setting like the DRC that has been subject to tremendous economic hardship and sharply declining levels of real income. Children from households that are relatively well off economically are expected to be more likely to be enrolled in school than children from less well-off households, who will be under greater pressure to contribute to the economic well-being of the household via work at home or in the labor market.

Gender is another likely determinant of school enrollment. Parents with limited resources are often not able to send all of their children to school. To the extent that boys are seen as a "better investment" than girls - either because boys are expected ultimately to have better labor market opportunities than girls or because girls are expected eventually to "marry out" of the family and hence not be as good a source of old-age support as boys - this will translate to higher enrollment rates for boys. In addition, given traditional gender roles, girls are more likely than boys to engage in work at home, and since labor market opportunities at the young ages under consideration here are quite limited, this is also expected to contribute to higher school enrollment rates for boys, other things equal.

There are two other factors linked to the demand for child labor at home that are likely to influence enrollment rates as well: the overall size of the household, and the number of young children in the household. We expect that there will be greater demand for child labor at home as households get bigger, resulting in lower enrollment rates for children (and especially girls) from larger households. Likewise, the presence of children under the age of 5 in the household signals a demand for child care, and in the DRC as elsewhere in sub-Saharan Africa, child care is often provided by school-age children, especially girls. Hence, female enrollment rates in particular are expected to be influenced by the presence and number of pre-school children in the household.

Place of residence (urban or rural) is also expected to influence the likelihood of a child being enrolled in school. Access to school is likely to be easier for urban youth as compared to rural youth, and opportunities for work by youth that contributes to household economic well-being are probably greater in rural areas. Further, the future payoff to schooling in the labor market is likely to be greater in urban places than in rural areas. Hence, we anticipate greater enrollment rates in urban places, other things equal.

As noted in the discussion of the literature found in the introduction, there 
often appear to be interactions among our three key variables - family economic well-being, gender, and place of residence. For example, differences in school enrollment by economic wellbeing have been shown in some studies to depend on gender and/or on place of residence. Our multivariate analyses below explore these possible interactions by estimating separate models by gender and by place of residence, in addition to an overall model for the full sample.

Parental preferences will also influence which children attend school. Educational attainment of the household head and the head's spouse are two relevant variables here: the greater the educational attainment of the head and spouse, the greater the likelihood that children will be enrolled in school, other things being equal. Likewise, we take into consideration the sex of the head of the household, as some studies have found that children (and especially girls) are more likely to be in school when the household head is female.

A child's relationship to the household head and the head's spouse is also pertinent here. While about two-thirds of the youth aged 6-14 in the survey were children of both the head and the spouse, one-sixth of the children were linked biologically to only one parent and a similar fraction were children who had been fostered in to their households. We anticipated that children of both the head and spouse were likely to have the highest enrollment rates, other things equal, while fostered-in children would have the lowest rates.

We also control for religion in the analyses of school enrollment, to allow for differences in preferences for children's schooling by religious group. Similarly, province is taken into consideration as well - with the exception of Kinshasa, which has residents from various ethnic groups, the provinces are each dominated by different ethnic groups, which may have different preferences for children's schooling.

The remaining determinant of children's school enrollment that we examine is the child's age. Here there are offsetting influences. Children are supposed to begin school at age 6 , but in rural areas in particular many parents prefer that their children be a bit older prior to beginning school. Even in urban centers like Kinshasa, there is a tendency for enrollment rates to rise with age for at least a few years beyond age 6 (Shapiro and Tambashe, 1999, 2001). As children get older, however, their prospective contributions to family well-being through work activity increase, and this will tend to reduce school enrollment, other things equal.

We turn now to an examination of the data, beginning with a descriptive overview and then continuing with a series of multivariate analyses.

\section{School enrollment : A descriptive overview}

The data analyzed here are from a 1999 survey on the demand for education in the Congo. More than 3,000 households from four of the country's II provinces, in the west of the DRC Bandundu, Bas-Congo, Kasai Occidental, and Kinshasa - were covered by the survey. There were more than 9,000 youth aged 6-24 in the surveyed households, and data were collected on the school enrollment of these youth as 
well as on various aspects of the house- holds within which they resided.

Figure 1. Enrollment status and rates by age, and other ratios, youth aged 6-24
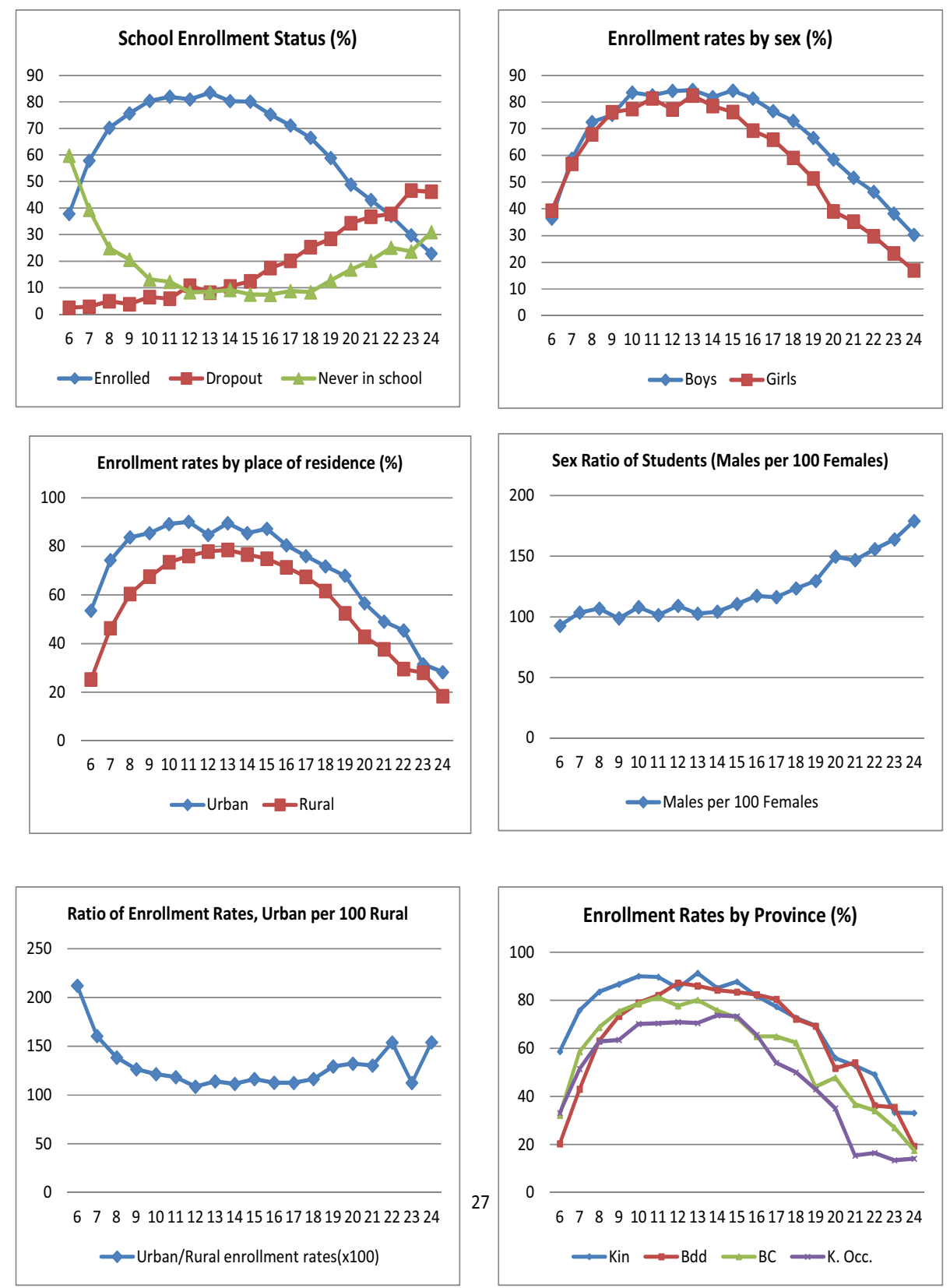

Figure I documents that for these to begin at age 6 , in fact rises from age youth covered by the survey, school enrollment, which officially is supposed 6 to age 13. This is a reflection of delayed entry to schooling, which is 
quite prevalent in rural areas in particular. Peak enrollment occurs roughly from ages 10-15, and corresponds to about 80 percent of youth at each age in this range. While this is well below the Millennium Development Goal of universal primary education, it seems reasonably high, especially given the adverse economic circumstances of the 1990 s. $^{3}$

Table I Enrollment rates by age, sex, place of residence, and province

\begin{tabular}{lccccccc}
\hline Characteristics & \multicolumn{7}{c}{ Age } \\
\cline { 2 - 7 } Sex & 6 & 9 & 12 & 15 & 18 & 21 & 24 \\
Male & 36 & 75 & 84 & 84 & 73 & 52 & 30 \\
Female & 39 & 76 & 77 & 76 & 59 & 35 & 17 \\
Place of residence & & & & & & & \\
Urban & 54 & 85 & 85 & 87 & 72 & 49 & 28 \\
Rural & 25 & 68 & 78 & 75 & 62 & 38 & 18 \\
Province & & & & & & & \\
Bandundu & 20 & 73 & 87 & 83 & 72 & 54 & 19 \\
Bas-Congo & 32 & 75 & 78 & 73 & 62 & 37 & 18 \\
Kinshasa & 59 & 87 & 85 & 88 & 73 & 53 & 33 \\
Kasaï-Occidental & 33 & 64 & 71 & 73 & 50 & 15 & 14 \\
Rate (\%) & 38 & 76 & 81 & 80 & 66 & 43 & 23 \\
\hline
\end{tabular}

Beginning at age 15, boys are distinctly more likely to be enrolled than girls, and urban youth have higher enrollment rates than rural youth, with the urban-rural differences being greatest at the youngest ages. The four provinces also differ by enrollment rates, with Kinshasa standing out as having especially high enrollment rates among those aged 6-II as well as having comparatively high rates for youth aged 15 and above.

Table I shows enrollment rates by age (at three-year intervals) and by sex, place of residence, and province. The table confirms some of the relationships in Figure I. At the youngest ages, enrollment rates of girls slightly exceed those of boys. By age 12, however, enrollment of boys is higher, and the gender gap generally gets larger as youth age. Enrollment rates are higher for urban youth than for their rural counterparts, with the differences being largest at the youngest ages. The highest enrollment rates are usually in Kinshasa, and this is especially the case for the two youngest age groups and for the oldest youth. For other ages, Bandundu shows comparatively high enrollment rates while the rates in BasCongo and Kasai Occidental are rela-

3. Lloyd (2005, Table 3-I) provides data on school attendance from Demographic and Health Surveys indicating that for youth aged 10-14 in Eastern and Southern Africa the attendance rates (reported separately by gender) averaged 72 percent, while in Western and Middle Africa the corresponding average was 62 percent. Hence, the DRC figures appear to be comparatively high. 
tively low.

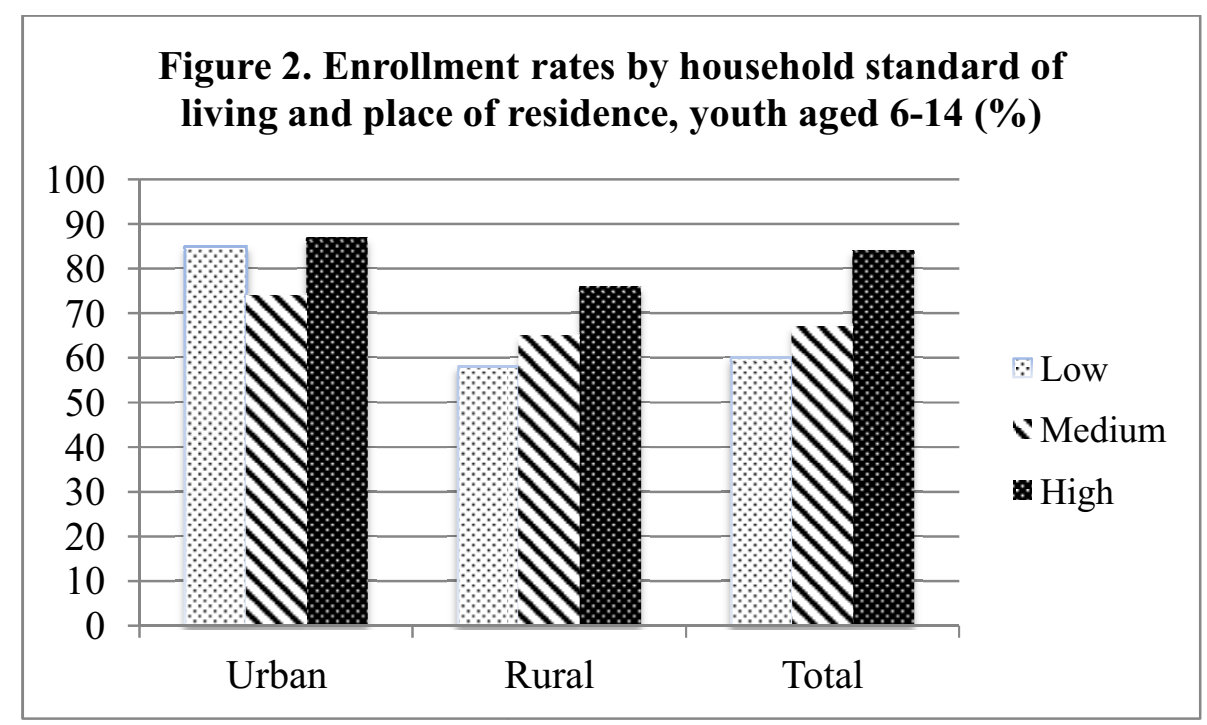

Enrollment rates by household standard of living and place of residence are shown in Figure 2. The classification of standard of living was based on a variety of housing characteristics (e.g., source of water, type of roof, toilet facilities, etc.), using multiple correspondence analysis (for details, see Mabika, 2010, ch. 5). Three groups are identified: low (poor), medium, and high. For the overall and rural samples, there is clearly a strong positive relationship between family economic well-being and enrollment rates. In the urban sample, however, this is not the case: children from poor households have a higher enrollment rate than those from medium households. We note, however, that the sample of poor urban children is small, consisting of fewer than 80 individuals.

We also examined bivariate relationships between school enrollment and the determinants of school enrollment discussed in the preceding sec- tion. For the most part, these relationships (not shown here) were statistically significant.

\section{Multivariate analyses of school enrollment}

We turn now to multivariate analyses. Since the dependent variable is binary, logistic regressions were estimated, with school enrollment as the dependent variable and with the previously-discussed determinants of school enrollment as the explanatory variables. Results from the overall model that we estimate are shown in Table 2.

That is, Table 2 shows the coefficients from the logistic regressions of being enrolled in school at the time of the survey, for the nearly 6,200 youth aged 6-14 covered by the survey, according to a wide variety of characteristics. These characteristics include sex of the child, relationship to the head of the household, province of resi- 
dence, household size, education of the household head and education of the spouse of the head, sex of the household head, our three-category measure of family economic well-being, place of residence (urban vs. rural), the child's age, religion, and the number of children in the household under the age of 5. As is apparent in the table, there were significant differences within each set of characteristics except for that of the sex of the household head.

Table 2 Determinants of school enrollment, full model

\begin{tabular}{|c|c|c|}
\hline Variables & Observations & Coefficient \\
\hline \multicolumn{3}{|l|}{ Child's sex } \\
\hline Male & 3194 & $0.233^{* * *}$ \\
\hline Female & 2996 & $\mathrm{RC}$ \\
\hline \multicolumn{3}{|c|}{ Relationship to household head } \\
\hline Child of head and spouse & 4060 & $\mathrm{RC}$ \\
\hline Child of one parent & 1034 & $-0.442^{* *}$ \\
\hline Fostered-in child & 1096 & $-0.408^{* *}$ \\
\hline \multicolumn{3}{|l|}{ Province } \\
\hline Bandundu & 1680 & RC \\
\hline Bas-Congo & 1375 & $-0.213^{*}$ \\
\hline Kasaï Occidental & 1272 & $-0.497^{* *}$ \\
\hline Kinshasa & 1863 & $-0.579^{* *}$ \\
\hline \multicolumn{3}{|l|}{ Household size } \\
\hline $\mathrm{I}-4$ & 520 & -0.123 \\
\hline $5-6$ & 1532 & -0.082 \\
\hline $7-9$ & 2407 & $\mathrm{RC}$ \\
\hline $10-12$ & 1060 & 0.036 \\
\hline $13+$ & 671 & $-0.354^{* *}$ \\
\hline \multicolumn{3}{|l|}{ Education-head } \\
\hline None & 794 & $-0.877^{* *}$ \\
\hline Incomplete primary & 1005 & $-0.823^{* *}$ \\
\hline Completed primary & 611 & -0.136 \\
\hline Incomplete secondary & 853 & $-0.248^{*}$ \\
\hline Completed secondary & 2175 & $\mathrm{RC}$ \\
\hline University & 752 & $0.943^{* *}$ \\
\hline \multicolumn{3}{|l|}{ Education-spouse of head } \\
\hline Not reported & 1108 & $-0.440^{*}$ \\
\hline None & 1343 & $-0.885^{* *}$ \\
\hline Incomplete primary & 981 & $-0.579^{* *}$ \\
\hline Completed primary & 570 & $-0.348^{*}$ \\
\hline
\end{tabular}


Incomplete secondary

Completed secondary or more

Sex of household head

Female

Male

Standard of living

Low

Medium

High

Place of residence

Urban

Rural

Child's age

$$
6
$$

7

8

9

10

II

12

13

14

\section{Religion}

Catholic

Protestant

Kimbanguist

Prayer group

Other

Children under the age of 5

None
1
2
$3+$

Constant

N

Prob $>\mathrm{Chi}^{2}$

Pseudo $\mathrm{R}^{2}$
727

|461

931

5259

1063

3042

2085

2628

3562

706

674

677

717

711

649

689

703

664

2687

1566

274

1475

188

1727

1856

1595

1012
$-0.251^{+}$

RC

0.236

RC

$-0.161^{+}$

RC

$0.706^{* *}$

$0.633^{* *}$

RC

RC

$1.092^{* * *}$

$1.691^{* *}$

$2.045^{* *}$

$2.339^{* *}$

$2.429^{* *}$

$2.356^{* * *}$

$2.621^{\text {** }}$

$2.343^{* *}$

RC

0.019

$-0.242$

$-0.234^{* *}$

$-0.069$

RC

$-0.298^{* *}$

$-0.347^{* *}$

$-0.219^{+}$

0.124

6190

0.000

0.203 
$\mathrm{RC}=$ reference category

** Significant at the .01 level.

* Significant at the .05 level.

+ Significant at the .10 level.

Boys were significantly more likely to be enrolled in school than girls, other things being equal. Compared to children of both the household head and spouse, children of only one of the two as well as fostered-in children were less likely to be enrolled in school. There were significant differences in school attendance by province of residence, with Bandundu province having higher enrollment rates than the other three provinces, ceteris paribus. ${ }^{4}$ Enrollment rates were significantly lower for children from households of 13 or more individuals, while greater schooling of the household head and spouse translated into higher school enrollment, with substantial differences across the different categories. ${ }^{5}$

Household standard of living was significantly related to the likelihood of a child being enrolled in school. Children from households of low economic status were slightly less likely to be enrolled in school than those of medium status, while those from higheconomic-status households were about twice as likely to be enrolled in school as children from the mediumstatus group. Children from urban households were almost twice as likely to be in school as compared to their rural counterparts. The likelihood of being in school rose sharply with age up through age $\mathrm{II}$, fluctuated a bit, and then fell at age 14. Children from households whose affiliation was prayer group were less likely to be in school than children from other religious groups. Finally, children from households where there were one or more children under age 5 were significantly less likely to be enrolled.

The results from Table 2, our full model, are for all youth aged 6-14. We also estimated models separately by sex, in order to determine if there were differences by sex in the effects on enrollment of household economic well-being, place of residence, and other variables. These models are reported in Table 3. It is still the case that there are significant relationships within most groups of variables. At the same time, there are some differences in the relationships for girls and boys. Consider first the coefficients for household standard of living. Among boys, there is a significant negative coefficient for those from the low group,

4. At first glance, this result seems to run counter to the graph in Figure I showing enrollment rates by province, in which Kinshasa has somewhat higher rates than Bandundu, overall. This reflects two factors: Kinshasa residents have a higher standard of living than Bandundu residents, and Kinshasa is entirely urban. Hence, the higher enrollment rates for Kinshasa in Figure I are picked up in part by the standard-of-living and urban residence variables in Table 2.

5. There were a substantial number of cases in which education of the spouse of the household head was not reported. Rather than delete these observations from the data, we have created a category called "not reported." The coefficient for this category in Table 2 is intermediate between the coefficients for incomplete primary and completed primary education. 
and a significant positive coefficient for those from the high group. Among girls, by contrast, there is no significant difference between the low and medium groups, while those from the high group indeed have higher enrollment rates.

Table 3 Determinants of school enrollment, separate models by sex

\begin{tabular}{|c|c|c|c|c|}
\hline \multirow[t]{2}{*}{ Variables } & \multicolumn{2}{|c|}{ Girls } & \multicolumn{2}{|c|}{ Boys } \\
\hline & $\begin{array}{c}\text { Observatio } \\
\text { ns }\end{array}$ & Coefficient & $\begin{array}{c}\text { Observation } \\
\text { s }\end{array}$ & $\begin{array}{c}\text { Coefficien } \\
t\end{array}$ \\
\hline \multicolumn{5}{|c|}{ Relationship to household head } \\
\hline $\begin{array}{l}\text { Child of head and } \\
\text { spouse }\end{array}$ & 1936 & RC & 2124 & RC \\
\hline Child of one parent & 491 & $-0.479^{* *}$ & 543 & $-0.419^{* *}$ \\
\hline Fostered-in child & 569 & $-0.439^{* *}$ & 527 & $-0.362^{* *}$ \\
\hline \multicolumn{5}{|l|}{ Province } \\
\hline Bandundu & 765 & $\mathrm{RC}$ & 915 & $\mathrm{RC}$ \\
\hline Bas-Congo & 694 & -0.147 & 681 & $-0.291^{*}$ \\
\hline Kasaï Occidental & 588 & $-0.575^{* *}$ & 684 & $-0.424^{* *}$ \\
\hline Kinshasa & 949 & $-0.497^{* *}$ & 914 & $-0.627^{* * *}$ \\
\hline \multicolumn{5}{|l|}{ Household size } \\
\hline $\mathrm{I}-4$ & 243 & -0.149 & 277 & -0.104 \\
\hline $5-6$ & 758 & -0.060 & 774 & -0.116 \\
\hline $7-9$ & 1184 & $\mathrm{RC}$ & 1223 & $\mathrm{RC}$ \\
\hline $10-12$ & 502 & -0.130 & 558 & 0.206 \\
\hline $13+$ & 309 & $-0.591^{* *}$ & 362 & -0.116 \\
\hline \multicolumn{5}{|l|}{ Education-head } \\
\hline None & 348 & $-0.787^{* *}$ & 446 & $-0.973^{* *}$ \\
\hline Incomplete primary & 458 & $-0.746^{* *}$ & 547 & $-0.920^{* *}$ \\
\hline Completed primary & 277 & -0.229 & 334 & -0.049 \\
\hline Incomplete secondary & 411 & $-0.275^{+}$ & 442 & -0.219 \\
\hline Completed secondary & 1124 & $\mathrm{RC}$ & 1051 & $\mathrm{RC}$ \\
\hline University & 378 & $1.028^{* * *}$ & 374 & $0.885^{* *}$ \\
\hline \multicolumn{5}{|c|}{ Education-spouse of head } \\
\hline Not reported & 516 & $-0.583^{*}$ & 592 & -0.258 \\
\hline None & 622 & $-0.891^{* *}$ & 721 & $-0.895^{* *}$ \\
\hline Incomplete primary & 505 & $-0.594^{* *}$ & 476 & $-0.547^{* *}$ \\
\hline Completed primary & 253 & $-0.474^{*}$ & 317 & -0.241 \\
\hline Incomplete secondary & 374 & -0.178 & 353 & -0.325 \\
\hline $\begin{array}{l}\text { Completed secondary } \\
\text { or more }\end{array}$ & 726 & RC & 735 & $\mathrm{RC}$ \\
\hline
\end{tabular}


African Population Studies Vol 26, 2 (Nov 20I2)

\section{Sex of household \\ head}

Female

438

Male

2558

$$
0.375^{+}
$$

493

0.081

Standard of living

Low

490

Medium

1465

RC

2701

RC

High

1041

Place of residence

Urban

1342

Rural

1654

$$
-0.021
$$

573

$\mathrm{RC}$

1577

$-0.309^{*}$

$0.620^{* * *}$

1044

RC

Child's age

6

7

8

9

10

II

12

13

14

344

317

337

324

363

329

322

353

307

\section{Religion}

Catholic

Protestant

Kimbanguist

Prayer group

Other

Children under the age of 5

None

I

2

$3+$

Constant

$\mathrm{N}$

Prob $>\mathrm{Chi}^{2}$

Pseudo $\mathrm{R}^{2}$
1308

734

118

747

89

803

904

802

487
$0.723^{* * *}$
RC

1286

1908

362

357

340

393

348

320

367

350

357

$\left.2.11\right|^{* * *}$

$\mathrm{RC}$

$-0.090$

$-0.531^{*}$

$-0.351^{* *}$

$-0.091$

1379

832

156

728

99

RC

0.116

0.015

$-0.114$

$-0.172$

$0.5 \mid 4 * *$

RC

$\mathrm{RC}$

$1.261^{* *}$

$1.911^{* *}$

$2.164^{* *}$

$2.627^{* * *}$

$2.616^{* *}$

$2.771^{* *}$

$2.807^{* * *}$

$2.594^{* * *}$

$\mathrm{RC}=$ reference category 
*** Significant at the .01

level.

* Significant at the .05

level.

+ Significant at the .10 level.

Age patterns of enrollment show consistently higher coefficients for boys than for girls. This reflects the earlier observation of a gender difference in favor of boys emerging only after the first several years of eligibility for school. Girls in very large households are significantly less likely to be enrolled in school, whereas household size is not significantly related to enrollment of boys. This result presumably is the outcome of a greater likelihood of girls working at home than boys. We anticipated that the presence of young children in the household would be more detrimental to girls' schooling as well, but this is not the case.

Table 4 Determinants of school enrollment, separate models by place of residence

\begin{tabular}{|c|c|c|c|c|}
\hline \multirow[t]{2}{*}{ Variables } & \multicolumn{2}{|c|}{ Urban } & \multicolumn{2}{|c|}{ Rural } \\
\hline & Observations & Coefficient & Observations & Coefficient \\
\hline \multicolumn{5}{|c|}{ Relationship to household head } \\
\hline $\begin{array}{l}\text { Child of head and } \\
\text { spouse }\end{array}$ & 1622 & $\mathrm{RC}$ & 2438 & $\mathrm{RC}$ \\
\hline Child of one parent & 434 & $-0.657^{* *}$ & 600 & $-0.335^{*}$ \\
\hline Fostered-in child & 572 & $-0.561^{* *}$ & 524 & $-0.339^{* *}$ \\
\hline \multicolumn{5}{|l|}{ Province } \\
\hline Bandundu & 96 & $\mathrm{RC}$ & 1584 & $\mathrm{RC}$ \\
\hline Bas-Congo & 265 & $0.717^{* * *}$ & 1110 & $-0.318^{* *}$ \\
\hline Kasaï Occidental & 404 & -0.039 & 868 & $-0.519^{* *}$ \\
\hline Kinshasa & 1863 & -0.003 & na & na \\
\hline \multicolumn{5}{|l|}{ Child's sex } \\
\hline Male & 1286 & 0.162 & 1908 & $0.260^{* *}$ \\
\hline Female & 1342 & $\mathrm{RC}$ & 1654 & $\mathrm{RC}$ \\
\hline \multicolumn{5}{|l|}{ Household size } \\
\hline $\mathrm{I}-4$ & 172 & $-0.401^{+}$ & 348 & 0.029 \\
\hline $5-6$ & 597 & $-0.389^{*}$ & 935 & 0.087 \\
\hline $7-9$ & 1116 & $\mathrm{RC}$ & 1291 & $\mathrm{RC}$ \\
\hline $10-12$ & 425 & -0.196 & 635 & 0.150 \\
\hline $13+$ & 318 & $-0.473^{*}$ & 353 & $-0.270^{+}$ \\
\hline \multicolumn{5}{|l|}{ Education-head } \\
\hline None & 168 & $-0.630^{* *}$ & 626 & $-0.965^{* *}$ \\
\hline Incomplete primary & 283 & $-0.892^{* *}$ & 722 & $-0.815^{* *}$ \\
\hline Completed primary & 233 & -0.088 & 378 & -0.160 \\
\hline
\end{tabular}


African Population Studies Vol 26, 2 (Nov 20I2)

Incomplete
secondary
Completed
secondary
University
Education-spouse of
head

Completed secondary

or more

Sex of household

head

Female

Male

Standard of living

$$
\text { Low }
$$

Medium

High

Child's age

6

7

8

9

10

II

12

13

14

Religion

Catholic

Protestant

Kimbanguist

Prayer group

Other
300

1008

636

551

218

294

224

345

996

$-0.068$

RC

$0.872^{* * *}$

$-0.280$

$-1.058^{* *}$

$-0.455^{*}$

$-0.577^{*}$

$-0.332^{+}$

$\mathrm{RC}$

465

2163

79

1003

1546

309

275

279

318

308

265

296

308

270

933

712

79

810

94
0.339

RC

0.444

RC

$0.781^{* *}$

$\mathrm{RC}$

$1.048^{* *}$

$1.706^{* *}$

$1.900^{* *}$

$2.326^{* * *}$

$2.298^{* *}$

$1.859^{* * *}$

$2.403^{* *}$

$1.743^{* * *}$

RC

$-0.457^{* * *}$

$-0.397$

$-0.496^{\text {** }}$

$-0.395$
553

II67

116

$1.220^{* *}$

557

1125

687

346

382

465

466

3096

0.234

RC

984

2039

539

$-0.616^{*}$

$-0.867^{* *}$

$-0.621^{* *}$

$-0.271$

$-0.206$

RC

$-0.255^{* *}$

RC

$0.709^{* *}$

397

399

398

399

403

384

393

395

394

1754

RC

854

0.152

195

$-0.221$

665

$-0.148$

94

0.091

Children under the age of 5

None

807

RC

920

RC

815

$-0.385^{*}$

1041

$-0.228^{*}$ 


\begin{tabular}{|c|c|c|c|c|}
\hline 2 & 620 & -0.069 & 975 & $-0.470^{* *}$ \\
\hline $3+$ & 386 & -0.178 & 626 & $-0.273^{+}$ \\
\hline Constant & & $0.674^{+}$ & & -0.126 \\
\hline $\mathbf{N}$ & \multicolumn{2}{|c|}{2628} & \multicolumn{2}{|c|}{3562} \\
\hline Prob $>\mathrm{Chi}^{2}$ & \multicolumn{2}{|c|}{0.000} & \multicolumn{2}{|c|}{0.000} \\
\hline Pseudo $\mathrm{R}^{2}$ & \multicolumn{2}{|c|}{0.191} & \multicolumn{2}{|c|}{0.185} \\
\hline
\end{tabular}

$\mathrm{RC}=$ reference category

na $=$ not applicable

${ }^{*}$ Significant at the .01 level.

* Significant at the .05 level.

+ Significant at the 10 level.

Urban youth are more likely to be in school than their rural counterparts, but the urban-rural gap is somewhat greater for girls than for boys. That is, girls benefit from urban residence somewhat more so than do boys. There is also a weakly significant positive coefficient for girls in femaleheaded households, but not for boys.

Our last set of results comes from estimation of models separately for children from urban and rural households. The results are shown in Table 4. Consider first gender differences. Among urban youth gender is not significant, while among rural youth boys are significantly more likely than girls to be enrolled in school, other things equal. This outcome corresponds to the larger urban-rural gap in enrollment among girls reported in Table 3.

There are higher enrollment rates in urban Bas-Congo as compared to urban areas in the other provinces, while in rural areas those in Bas-Congo and Kasai Occidental are less likely to be enrolled than those in Bandundu. In both urban and rural places, children of either the head or spouse (but not both) as well as fostered-in children are less likely to be in school and education levels of the household head and spouse are significantly positively linked to enrollment. Youth from high-standard-of-living households are significantly more likely than those from medium households to be enrolled, in both urban and rural places. By contrast, enrollment rates of those from poor rural households are significantly lower than those from medium households, but there is not a significant difference for the small number of urban youth in the low category. Coefficients increase with age more rapidly for rural youth, reflecting the much lower rural enrollment rates at the youngest school ages. And the presence of children under age five appears to be a more significant inhibitor of enrollment among rural youth than among their urban counterparts.

Some of the results of interest from the different multivariate analyses are summarized in Figures 3 and 4, showing predicted probabilities of school enrollment by age for various characteristics. These predicted probabilities were calculated assuming the reference category for all characteristics other than those highlighted in the figures. 
Figure 3. Predicted Probability of School Enrollment, by Gender and by Socioeconomic Status

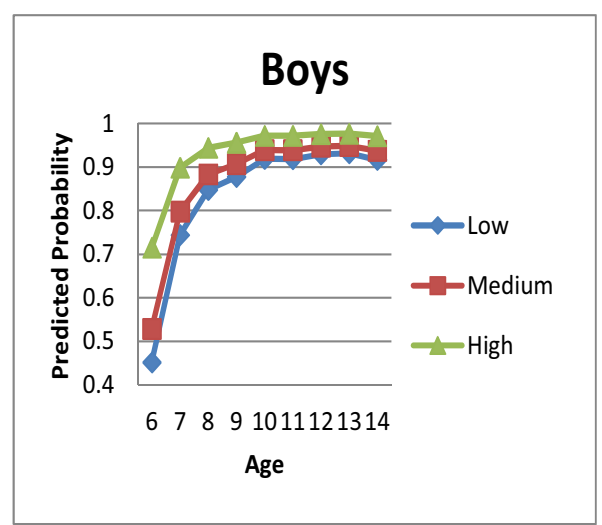

*Calculated from data in Table 3.

More specifically, Figure 3 shows the predicted probabilities of enrollment by age and by socioeconomic group, separately for girls and boys, based on the results in Table 3. Among boys, predicted enrollment at each age rises in going from the low to the middle and then to the high standard-of-living group, and there are especially large increases with age at the youngest ages. Among girls, by contrast, the two lower standard-of-living groups have virtually identical predicted probabilities of being enrolled in school, and only in moving to the high group does one see a distinct increase in the predicted probability of being enrolled. In general, then, improved economic well-being is more consistently associated with higher school enrollment among boys than among girls.

Further, the differences by standard of living in predicted enrollment rates were greatest at ages 6 and 7 for both

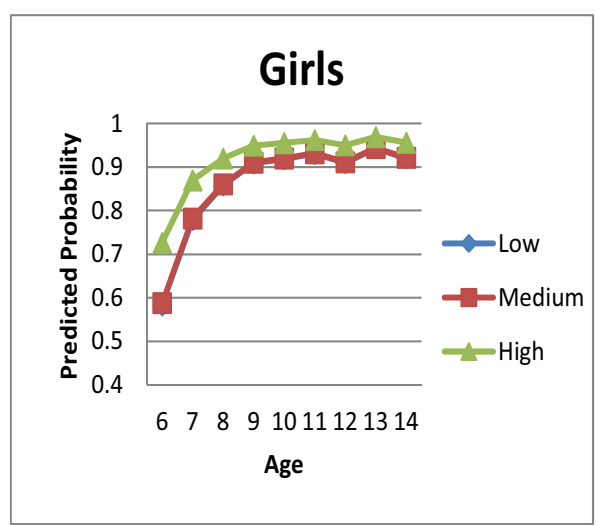

girls and boys. Clearly, children who are not economically advantaged are much less likely to begin school on time as compared to their better-off counterparts. Other things equal, this means that even when enrollment rates are similar across the different standard-ofliving groups at later ages, youth from economically advantaged households will be farther along in school than those from economically disadvantaged households.

Figure 4 shows the predicted probabilities of enrollment by age and by urban and rural residence within each province, based on the results in Table 4. Not surprisingly, given the large and highly significant coefficient for urban youth in Table 2, these youth are more likely to be in school than their rural counterparts in each province. The predicted enrollment rates rise with age across the board, and the rural-urban gap in enrollment is very large at the 
youngest ages, diminishing progressively to more modest levels by ages 10 or II. Rural youth are much more likely than their urban counterparts to begin school at a later age, similar to the delayed entry to school that we saw for youth from low standard-of-living households. A direct consequence is that while at later ages the rural-urban difference in enrollment rates has become small, urban youth will have a decided advantage over their rural counterparts in terms of the actual level of educational attainment.

Figure 4. Predicted Probability of School Enrollment, by Province and by Place of Residence
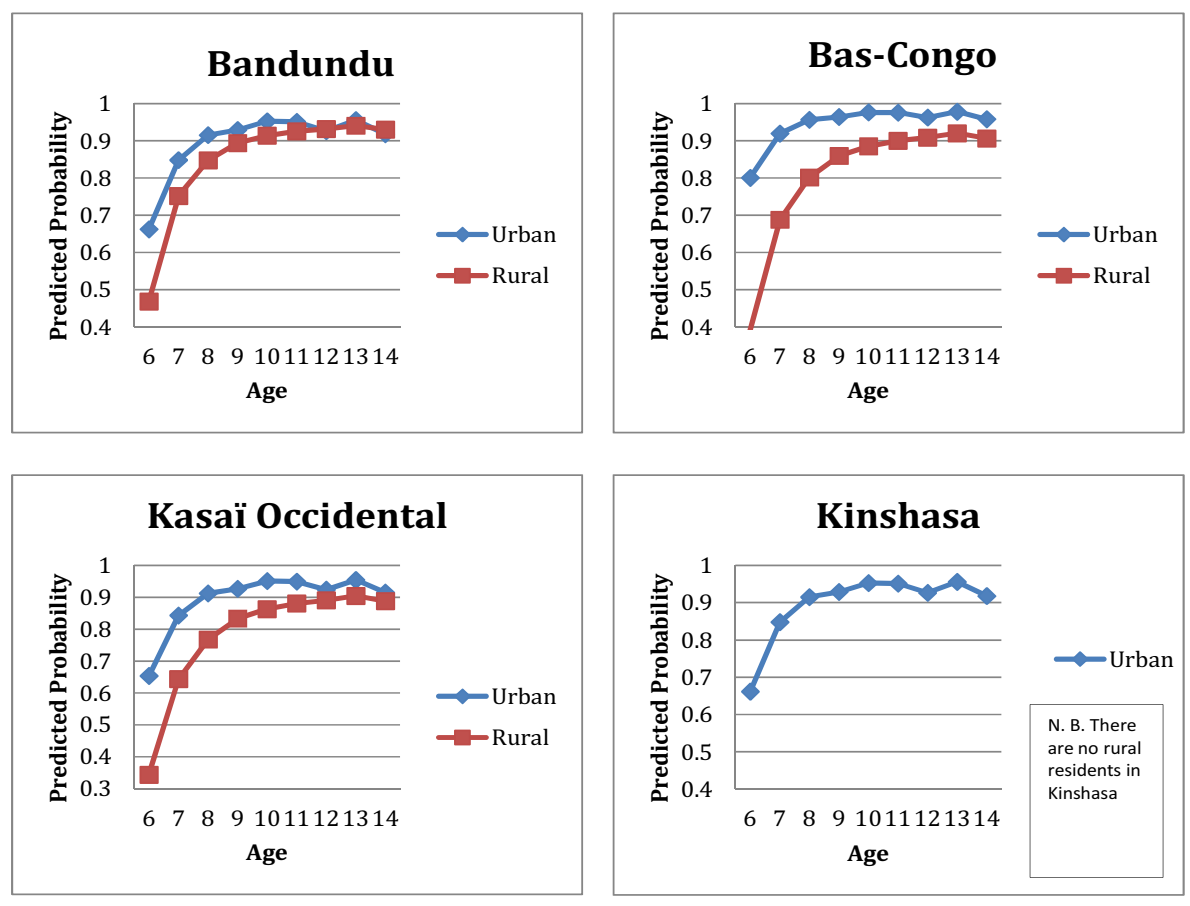

*Calculated from data in Table 4.

\section{Summary and implications}

This paper has presented and analyzed data on school enrollment in four western provinces of the Democratic Republic of the Congo. The data are from a 1999 survey, which was carried out at a time when the DRC was close to the end of a decade-long period of disastrous economic performance. Despite the extremely adverse economic conditions, school enrollment rates were relatively high for youth aged $10-14$, as compared to findings from DHSs for elsewhere in the region (Lloyd, 2005). This bears witness to the strong demand for education manifested by Congolese parents. At the same time, family economic well-being, gender, place of residence, and a wide variety of other factors were clearly linked to the school enrollment rates of youth aged 6-14. 
Family economic well-being was an important determinant of the likelihood of school enrollment of youth. This factor was more strongly linked to the enrollment of boys than to that of girls, however. That is, among boys, moving from low to medium to high standard of living was associated with progressive increases in the likelihood of being enrolled, whereas among girls, improvement from the low group to the medium group was inconsequential, and enrollment rates increased significantly only in moving from the medium group to the high group. Further, children from poor and medium economic well-being households appear to be considerably more likely to delay entry to school as compared to their counterparts from the high standard-of-living group. The particularly adverse economic circumstances of the DRC in the decade leading up to data collection may well have contributed to both of these outcomes.

Analysis of enrollment of boys and girls jointly in Table 2 showed that, other things equal, enrollment rates are higher for boys, for the most part. At the same time, disaggregation by place of residence (Table 4) documented that girls did better relative to boys in urban places, where enrollment rates are higher in general, as compared to rural places. Elsewhere in sub-Saharan Africa, other researchers have found that adverse economic circumstances and poverty are associated with gender differences in schooling favor of boys (e.g., Glick and Sahn, 2000; Lloyd and Hewett, 2003; Kobiané, 2007), but our results show that in urban places in the western DRC, there is no significant gender difference in school enrollment, other things equal. Delayed entry to school also characterizes rural and poor youth as well.

In comparing our findings with those of other studies focused on the influences of economic well-being, gender, and place of residence on school enrollment, we find some similarities as well as some differences. For example, we noted earlier that the multi-country study of Huisman and Smits (2009) found a disadvantage for rural girls compared to urban girls that was not present among boys. Our separate analyses by gender (Table 3) indeed found a significant disadvantage for rural girls, but there was also a slightly smaller and significant disadvantage for rural boys. Glick and Sahn (2000) found that higher economic well-being in Conakry contributed to greater investment in schooling of girls but not boys, while we found, by contrast, a stronger link between economic well-being for boys than for girls. Ersado (2005) concluded that poverty drives schooling decisions in rural areas but not in urban places. Consistent with that conclusion, we found in Table 4 that poverty was not a handicap in urban places but was in rural settings. Kazeem et al. (20l0) concluded that the disadvantage of rural youth in Nigeria regarding schooling was almost entirely accounted for by differences in household wealth. By contrast, our results in Table 2 make it clear that even after controlling for household economic well-being, there remains a significant disadvantage of rural youth as compared to their urban counterparts.

As noted above, numerous other factors were also linked to enrollment rates of these youth. Particularly note- 
worthy in this regard is the strong impact of educational attainment of both the household head and the head's spouse. Since over time the trend has been toward increased schooling in the DRC and elsewhere, this implies that this trend will be self-reinforcing, as better-educated parents will be more likely to keep their children in school.

The paper began by evoking the Millennium Development Goal of universal primary education. The western part of the DRC examined here shows maximum youth enrollment rates on the order of 80 percent, and hence is distinctly below the MDG goal. At the same time, in view of the extremely adverse economic circumstances that were prevalent at the time of the data collection, the observed enrollment rates are distinctly higher than they might have been. The Congolese economy has been improving since the end of the 1990s, for the most part, and hence one may anticipate further increases in school enrollment rates. But the analyses in the paper clearly indicate the groups where extra efforts must be made if universal primary education or something close to it is to be realized: girls, and especially those from economically disadvantaged families from rural areas, and also boys from economically disadvantaged families in rural areas.

From a policy perspective, it should be noted that during the 1990s, in addition to international efforts such as "Education for All," the DRC, in collaboration with UNICEF, promoted a campaign for "Toutes les filles à l'école" [All girls in school]. This may well have contributed to the more rapid increase in schooling of girls than of boys. A second policy-related aspect is that construction of schools that provide rural youth with easier access to education would appear to be a desirable means of increasing enrollment rates for those youth with low enrollment rates. It also seems desirable to encourage parents in rural areas to send their children to school when they are eligible, rather than delaying school entry. However, this is an area where research on the consequences of delayed entry to school would be useful for purposes of identifying the effects of this practice. This suggests studying school achievement, and not simply enrollment. An additional issue for future research is to study the factors associated with school-age youth being not enrolled in school (both dropping out and never enrolling are relevant here). In this regard, biographical surveys rather than simply cross-sectional surveys would be especially desirable.

\section{References}

De Herdt, Tom. 2000. Surviving the transition: Institutional aspects of economic regress in Congo-Zaire, doctoral dissertation in economics, University of Antwerp.

De Herdt, Tom and Stefaan Marysse. 1997. "Against all Odds: Coping with Regress in Kinshasa, Zaire," European Journal of Educational Research, Vol. 9, No. I: pp. 209-230. Ersado, Lire. 2005. "Child Labor and Schooling Decisions in Urban and Rural Areas: Comparative Evidence from Nepal, Peru, and Zimbabwe, World Development, Vol. 33, No. 3: pp. 455-480.

Glick, Peter and David Sahn. 2000. "Schooling of Girls and Boys in a 
West African Country: The Effects of Parental Education, Income, and Household Structure," Economics of Education Review, Vol. 19, No. I, pp. 63-87.

Heston, Alan, Robert Summers, and Bettina Aten. 20II. Penn World Table Version 7.0. Center for International Comparisons of Production, Income and Prices, University of Pennsylvania.

Hugon, Philippe. 2007. "Variables démographiques et développement. Le cas de l'éducation et de la santé," in Benoît Ferrey (ed.), L'Afrique face à ses défis. Un avenir incertain. Paris : AFD-CEPED-Karthala, pp. I55- 196.

Huisman, Janine and Jeroen Smits. 2009. "Effects of Household- and District-Level Factors on Primary School Enrollment in 30 Developing Countries," World Development, Vol. 37, No. I: pp. 179-193.

Kaboré, Idrissa and Marc Pilon. 2003. "Intra-urban enrolment disparities in Ouagadougou." Background paper prepared for the Education for All Global Monitoring Report 2003/4, Gender and Education for All: The Leap to Equality, 2004/ED/EFA/ MRT/PI/3I, UNESCO.

Kazeem, Aramidé, Leif Jensen, and C. Shannon Stokes. 2010. "School Attendance in Nigeria: Understanding the Impact and Intersection of Gender, Urban-Rural Residence, and Socioeconomic Status," Comparative Education Review, Vol. 54, No. 2: pp. 295-319.

Knodel, John and Gavin W. Jones. 1996. "Post-Cairo Population Policy: Does Promoting Girls' Schooling Miss the Mark?", Population and Development Review, Vol. 22, No. 4: pp. 683-702.
Kobiané, Jean-François. 2007. "Ecole et travail des enfants dans les pays du sud: Situation actuelle et perspectives, " in Marc Pilon (ed.), Défis du développement en Afrique sub-Saharienne. L'enjeu du développement. Paris: Les Collections du CEPED, pp. 185-204. Lange, Marie-France. 2007. "Espaces scolaires en Afrique francophone," Ethnologie Française, Vol. 37, No. 4: pp. 639-645.

Lloyd, Cynthia B. 2005. "Schooling," in Cynthia B. Lloyd (ed.), Growing Up Global: The Changing Transitions to Adulthood in Developing Countries. Washington, DC: National Academies Press, pp. 67-167.

Lloyd, Cynthia B. and Ann K. Blanc. 1996. "Children's Schooling in SubSaharan Africa: The Role of Fathers, Mothers, and Others," Population and Development Review, Vol. 22, No. 2: pp. 265-298.

Lloyd, Cynthia. B. and Paul C. Hewett. 2003. "Primary Schooling in SubSaharan Africa: Recent Trends and Current Challenges." Working Paper No. 176, New York, NY: The Population Council.

Mabika, Crispin. 2010. Pauvreté des ménages et accès des enfants à la scolarisation et à la santé en République Démocratique du Congo. Doctoral dissertation. Louvain-laNeuve, Belgium: Université Catholique de Louvain.

Moguéorou, Laure. 201I. "La démocratisation de l'école à Dakar : les Enseignements d'une enquête biographique," Autrepart, Vol. 3, No. 59 : pp. 9I-108.

Pilon, Marc and Madeleine Wayack. 2003. "La démocratisation de 
l'enseignement au Burkina Faso : que peut-on en dire aujourd'hui ?," Cahiers d'études africaines, Vol. 43 (I-2), No. 169-I70 : pp. 63-86.

Proteau, L. 1998. "Itinéraires précaires et expériences singulières. La scolarisation féminine en Cte d'lvoire," in Marie-France Lange (ed.), L'école et les filles en Afrique. Scolarisation sous conditions. Paris : Karthala, pp. 27-7I.

Rebouha, Fafa and Pascal Pochet. 20I I. "Pauvreté et accès à l'éducation dans les périphéries d'Oran," Autrepart, Vol. 3, No. 59: pp. I8I198.

Schultz, T. Paul. 1993. "Investments in the Schooling and Health of Women and Men: Quantities and Returns," Journal of Human Resources, Vol. 28, No. 4: pp. 694-734.

Shapiro, David. 2010. "Gender, Economic Well-being, and Children's Access to Schooling in Kinshasa: Outcomes in the Presence of Prolonged Economic Crisis." Paper presented at the Annual
Meeting of the Population Association of America, Dallas, TX.

Shapiro, David and Basile O. Tambashe. 1999. "Gender, poverty, and school enrollment in Kinshasa, Congo," in Union for African Population Studies, The African Population in the $21^{\text {st }}$ Century, Proceedings of the Third African Population Conference, 6-10 December 1999, Durban, South Africa: pp. 587-6I7.

Shapiro, David and Basile O. Tambashe. 200I. "Gender, Poverty, Family Structure, and Investments in Children's Education in Kinshasa, Congo," Economics of Education Review, Vol. 20, No. 4, pp. 359-375.

Shapiro, David and Basile O. Tambashe. 2003. Kinshasa in Transition: Women's Education, Employment, and Fertility. Chicago: University of Chicago Press.

Shapiro, David and Eric Tollens. 1992.

The Agricultural Development of Zaire. Brookfield, VT: Avebury/ Ashgate Publishing Company. 